\title{
Efficient daylighting approach by means of light-shelve device adequate for habitat program in Aarhus City
}

\author{
Asaad Almssad $^{\mathrm{a}^{*}}$, Amjad Almusaed $^{\mathrm{b}}$ \\ ${ }^{a}$ Department of Engineering and Chemical Sciences, Karlstad University, Karlstad, Sweden \\ ${ }^{b}$ Department of Sustainable architecture, Archcrea Institute, Aarhus, Denmark
}

\begin{abstract}
The concepts of light shelves consist of windows that have face towards the sun, which receive a vast quantity of energy that could be used for healthy day lighting. This paper debates a main assessment, investigates the optimization of daylight requirement by means of light shelves system. An experimental test was carried out assessing the measurements and lighting simulations of a model of a building in order to elucidate the characteristics of indoor lighting. Light shelf is an architectural element that permits daylight to enter deep into a building. It constitutes an optimal solution for an incorrect building orientation and less sunny days. The essential objective of this study is to highlight the vital role of light shelves in residential buildings in northern Europa where the requirement is to improve the daylight in the interior functional spaces. The main objects of this paper are to investigate the effect of daylight in the interior functional spaces using light shelves, the effect of natural light diffusion in interior space in the period of low daylight season, and glare effect in this field. This paper investigates a procedure for analysing the daylight performance using software habitat function program. The experiment focuses on the difference between light shelves placed in the interior, vs. on the exterior.
\end{abstract}

Keywords: Light shelves; daylighting; habitat space; optical comfort

\section{Introduction}

The relationship between people, daylight, and architectural design is intimate. Daylight introduces life, variation, and drama into otherwise banal spaces. Throughout the history of civilization our buildings have articulated this relationship. Daylight as a design variable can profoundly influence building orientation, form, scale, the character of interior spaces, and the way that interior space is perceived [1]. The diminishing of energy uses in buildings and progression of consumer physical comfort by means of practical daylighting strategies take on more and more meaning and relevance. In this process, we have to optimize daylight uses in functional spaces to reduce using of artificial light power. Therefore locating optimality of the habitant functions in building design, and control of the daylight requirements is a primary aspect in this process. The idea of effective daylight in an architectural space is both an art and a science. The main challenge meeting the architect is to admit only as much light as necessary and allocate it consistently throughout the space without introducing glare or heat. Daylighting, as a part of architectural design, was handled more often as an art, while as a science it was in the hands of a very few experts [2]. The planning of profound inner spaces and the growing dependence on artificial lighting as an addition to daylight are but two of the factors that are tending to modify the emphasis on daylight and to support a more serious position for the function of windows.

Why are light shelves essential in buildings from Aarhus city?

Locations in northern Europe, in Denmark and more precisely in Aarhus city are distinguished by shorter days in winter and longer days in summer. In terms of the availability of daylight, therefore, these

\footnotetext{
* Manuscript received March 25, 2014; revised June 23, 2014.

Corresponding author: Asaad Almssad; Tel.: +46 5470013 98; E-mail address: Asaad.almssad@kau.se

doi: $10.12720 /$ sgce.3.4.441-453
} 
locations are subject to larger seasonal variations than places in central Europe. Because the position of the sun is lower in general, they are subject to deficiencies in (sun) light and heat in the winter especially. For that reason, maximizing the influx of daylight is of utmost importance at these latitudes. It is good to know that the overcast sky typical of the north is brightest around the zenith. The luminance measured there is around three times higher than that at the horizon. In northern zones and coastal regions, therefore, more natural light can be brought into buildings via skylights than with the usual lighting from the side [3]. Therefore light shelves turn out to be an indispensable method to remediate the negative effect of daylight in this climatic zone; even with the challenges in distributing this free lighting energy such as lighting geometry and glare. In order for illumination to be useful, it must come from overhead [4]. Light shelves disperse sunlight efficiently; consequently, the amount of heat energy that is supplied to internal space by light shelf systems is not more than using of active form of energy for lighting [5]. For improved daylight penetration in light shelf systems we have to take in to account using of a clearer glass in the part above the shelves for high daylight admission and using a tinted glass below for glare control and reduced glare. Today design software for architects and engineers are dotted with sun light simulation programs, where simulation models can estimate the annual energy consumption for artificial light or the influence of daylight on the thermal performance of the construction. We have worked with this type of software to integrate results in our design process and include elements in building design for the next step of research. Synthesis of these results sustain engineers and architects with tools to purpose the ideal daylight performances and requirements upon habitat buildings.

\section{Light Comfort Based on Luminous Ambience and Lighting Factors}

The light by which we see the spaces we inhabit gives them their own peculiar character: it may make them intimate or over-whelming, comforting or threatening. The most efficient way of using light shelves in temperate habitat buildings is for improving interior daylighting quality. Natural light contributes to energy saving, and at the same time increases the state of light comfort for internal functional space. The idea of integrating external daylight in interior space design can strengthen the value of architectural design work and have a great influence on the architectural model of the sustainable building design. Great changes are taking place in the training of architects in order to meet the problems of modern building practice. There are different light factors required for each architectural program, where needed illumination varies according to after these factors. Fig. 1 presents the light factor in different architectural programs.

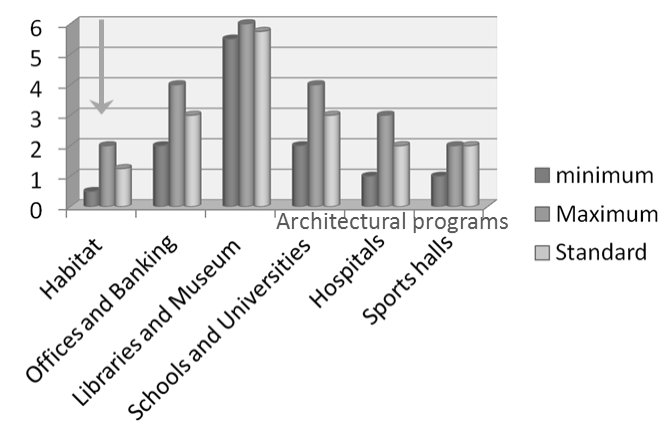

Fig. 1. Light factors in different architectural programs.

The notion of comfort and luminous ambience refers to the distribution of luminance and chromatic ties on the interior envelope of a space which is one of several important aspects of the experience of interior ambience and light. Luminance and chromatic ties are at present not often studied as far as comfort in buildings is concerned. Sun lighting and the concept of sustainable architecture are inseparable considerations when designing an edifice because of the historical and practical significance of natural lighting in architecture. Many researches in architectural engineering fields, illustrate that windows can 
occupy approximate 30-40\% of the façade in temperate climates [6]. The field of day lighting is as old as architecture itself. Recent advances in window technology have opened up new opportunities for reducing artificial lighting requirements in buildings. To get light into the building is the essential function of windows; therefore it symbolizes the essential part of any architectural element, which permits the daylight to penetrate into interior spaces, beside other roles of windows such as views and access to fresh air. It had a main influence upon the low energy building concept, as the weakest energetic element that affects the building form and its functions. A daylight factor (DF) is the ratio of inner light level to outside light level and is calculated by dividing the horizontal work plane illumination indoors $\left(E_{i}\right)$ by the horizontal illumination on the roof of the building being tested $\left(E_{o}\right)$ and then multiplying by 100 .

$$
D F=\left(E_{i} / E_{o}\right) \times 100 \%
$$

Natural daylight factors are employed in architecture and building design aimed at providing better evaluation of the internal natural lighting levels, and determining if they will be sufficient for the occupants of the space to carry out their normal activities [7]. The concept of daylight factor has one great advantage; although the daylight illumination out of doors may increase or decrease, the daylight factor will more or less remain consistent, because the interior illumination is also changing in step with the exterior daylight. Day light factors differ for different habitat functions, where a light factor 2 is a maximum day factor for working and study areas, and 0.5 is optimum for bathroom and habitat area, such as in our study. Fig. 2 shows interaction between Light factors and human activity in different habitat functions.

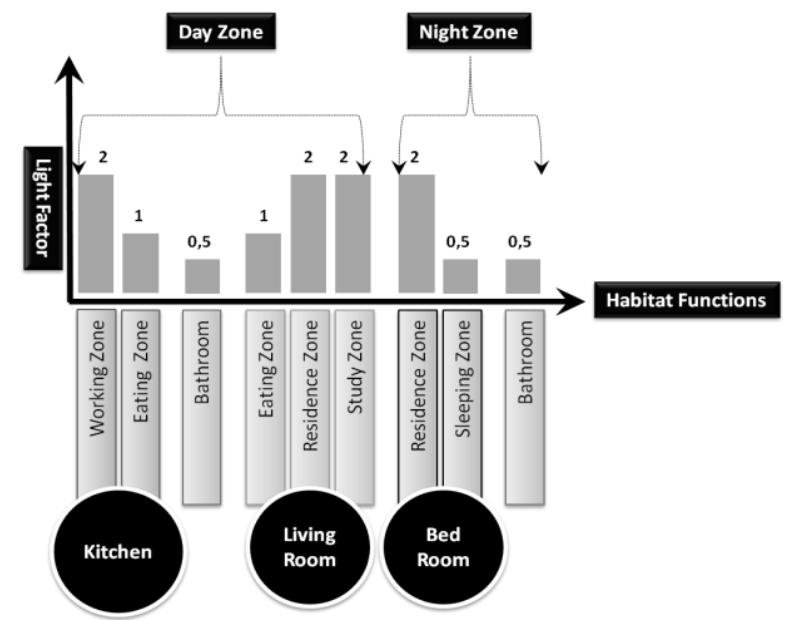

Fig. 2. Interaction between light factors and human activity.

These factors play important roles for architects and designers in the conception process. Therefore the daylight factor is not only a convenient measure of the interior lighting; it also gives architects and designers a better idea of the subjective impression of the daylight than what would be obtained from expressing the illumination in absolute values.

In this matter, the primary difference between daylight and artificial lighting is that the former is subject to considerable variation throughout the day in temperate climates and, because of this variability in intensity, it has become the standard practice in Britain and northwest Europe to specify the required daylight in terms of 'daylight factor' and not in absolute values (i.e. lux) as for artificial lighting. Window orientation in a habitat space is often dictated by views and light factors other than optimal solar gain. The concept of scalar illumination has the advantage that it allows the illumination to be specified in terms which allow for the three-dimensional nature of the lighting process and are appropriate for many visual tasks [8]. However, the scalar method is not yet accepted for general use and, while it gives a good indication of the way in which light fills a room, it is the luminance distribution on all visible surfaces in 
an interior which governs one's impression of the lighting character. In any habitat, the requirements for an efficient natural light factor vary by the habitat functions and human activity.

\section{Lighting Efficiency and Window Orientation}

The sunlight indicator can be used to select the best orientation for a building in order to meet the requirement for at least one hour of sunlight for ten months of a year. Such orientations have been worked out for buildings of different plan form. The fundamental unit, the lumen, measures the rate of flow of light in terms of its visual effect. To a normal observer, one lumen of blue light has the same lighting effect as one lumen of yellow although the powers, measured in watts, are different. In daylighting model the 'rate of flow' of light is of little practical interest so other units derived from the lumen are used more often [9]. The visible movement of the sun across the sky is due to the rotation of the earth around the sun and around its own axis, but the rise and fall of daylight at a point on the earth's surface is easier to follow if we revert to the primitive notion of a permission static earth and a circulating sun. The sun's apparent orbit on any day of the year can then be represented on an orthographic projection of the unit hemisphere [10]. Le Corbusier ( 1887-1965) French famous architect and urban planner has argued that, the ribbon window at the height of the balustrade in description provides good, uniform illuminance distribution along the façade but does not adequately illuminate the depths. His claim that the horizontal ribbon window results in illumination values eight times higher than a vertical window is just as inaccurate as the lighting properties he attributes to it. Fig. 3 shows the historical sketches designed by famous architect Le Courbusier [3].

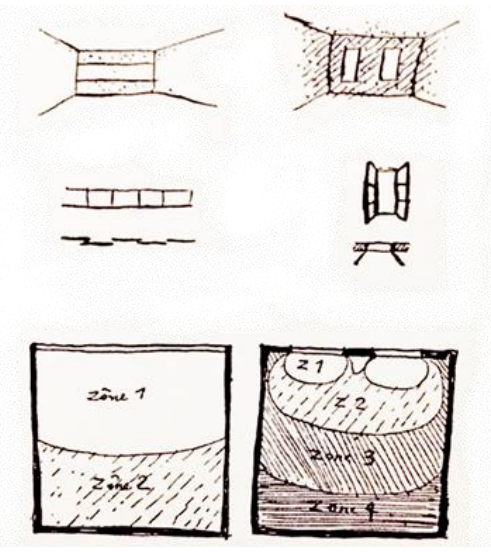

Fig. 3. Sketches by Le Corbusier illustrating that the ribbon window allegedly provides more and better light than the traditional vertical window format.

The illuminance penetrations through the window, varies significantly by season. Since the solar altitude is higher in summer, the penetration in summer was more tilted toward the window adjacent than in spring and fall. However, extreme illumination was produced that touched the midpoint of the functional space in winter, probable because direct solar radiation incoming from below the light shelf was high in winter when solar altitudes are lower. The lighting environment in summer was consequently more reliable than that in other seasons [11]. The problems of day lighting involve the assessment of lighting generated from natural sources (sun and sky) at a certain reference point. It is therefore a matter of analyzing the light flux generated by these sources and the illumination they produce. Sky luminance varies according to a series of meteorological, seasonal, and geometrical parameters that are difficult to codify. In view of this problem some models of standard skies have been worked out, and simplified references can be made to some other limited conditions [12]. The level of daylighting on the floor of the habitat space in the building will vary throughout the day and around the year due to the angle of incidence of the sun on the building surface. An obvious characteristic of daylight is the quality in which it varies from season to season and even from minute to minute. 
This characteristic variability and the "living" quality of daylight, as it is sometimes called, is not necessarily a disadvantage. Under some circumstances a varying illumination may assist concentration, as measured by the span of attention. It does mean, however, that daylight prediction cannot usefully aim at a high degree of accuracy, and that design criteria have inevitably to be based on a statistical treatment of meteorological data

The depth of the inner space has a direct effect on the intensity of illumination as well. If a space is modeled, keeping the floor-to-ceiling height and the area and location of the window constant, changing the room depth will cause a change in light intensity [1]. For an efficient sustainable architecture, it is essential to understand that the quality and quantity of natural light that reach inner space depend on window orientation, form, height, and dimension. Orientation towards the east or west receives large amounts of solar energy in the morning period and in the same time in the afternoon. The westerly orientation for example, is disadvantages in the afternoon, where the sunlight becomes horizontal in the summer.

The development of an appropriate "feel" for regional daylighting climates is important for successful architecture, as there remain so many aspects of daylighting design which it is not possible to incorporate into any formal quantitative design process. The north direction in the northern hemisphere is totally different; it's without a direct sunlight, consequently the lighting in this position is very constant in light and temperature. The East and west parts of building get a little amount of sun light in autumn, spring and winter, but it is excessive in the period of summer [13]. A Well designed window improves optical comfort year round. The major meaning of good window functions shows that windows are limited opening that permits light to penetrate in to inner space.

\section{Light Shelves Hypothesis, Benefits and Configuration}

\subsection{Light shelves hypothesis}

The aspects of technology; which until recently were left in the hands of specialists, are now included in the curriculum of the schools of architecture, and are ready to be accessed by the researchers on many aspects of building science. Over the last years, increasing attention has been given to the building research area in order to study these aspects with more concern for the human beings and their environment. The criterion of the efficiency of a building lies finally with the assessment by the human occupants [2]. The illumination values are the first quantitative parameters that must be verified in order to establish the visual comfort conditions in internal environment. From the architectural point of view, the luminous ambience is defined as the part played by light in the way an environment influences a subject. The majority of old buildings styles from northern Europe are a part of Art-Nouveau and New Classicism architectural styles, where the projects that are endowed with optimal daylight solutions are moderate. Thus Light shelves present an optimal and practical solution to solve the mistakes of design in old building, and incorrect architectural solutions of windows size, form, and placement. Sometimes the system becomes efficient when we change architectural functional space, where illumination requirement are modified [14]. The illuminance distribution of the ceiling indicated that illuminance was high at the window and that reflected diffuse light reached the back of the interior space. The natural skylight is best fitted for the majority of purposes, because of the human eye's optimal physiological adaptation to this form of light supply. The science and art of lighting depend upon the adaptability of the eye to function with reasonable efficiency in a wide range of conditions. A light shelf system contains a reflecting surface located inside or outside the window's structure. The ceiling then distributes the light into the interior space. Light shelves don't work optimally in all buildings where the number of overcast days is considerably higher than the number of clear, sunny days at the project place.

\subsection{Light shelves economic benefit}

Light shelves on the South facing façades of building remarkably increase the daylighting quality and quantity. The main advantages of light shelves are:

- Reduce cooling cost in summer time 
- Increases light penetration in inner functional spaces and diminish effective glare

- Daylighting increases the degree of health and physical comfort

- Affords protection for windows in the building and decreases leaks and wall moisture problems

- Improves inner space illumination through improvement of light distribution, which can lead to glare reduction

- It possesses a double role as shading device, improving the inner spaces illumination

This devise, which is most effective in southern orientations, improves daylight penetration, creates shading near the window, and helps reduce window glare [15]. This increases the cooling load in hot weather and decreases the heating load in cold and temperate climate weather.

\subsection{Light shelves condition and configuration}

The main portion of a light shelf system is a horizontal device placed in the exterior or interior. The horizontal light-reflecting overhang is placed above eye-level and has a high-reflectance upper surface. It can throw all the energy of direct sunlight into the space. In contrast, using shading to tame sunlight for daylighting leaves most of the potential day lighting energy outside the building. For a well-designed and functional light shelf system, we have to take into consideration [6]:

- A good treatment of windows. The lower part of the window under the light shelf system requires proper treatment to avoid the effect of glare

- The window has to be placed in direct sunlight in order to obtain an efficient system. However the lighting levels are still too unstable for any technical uses.

- The operative system function of light shelf is offered by a modest reflecting surface, it could be made of an special form of aluminum foil

- The distribution function of day lighting comes from the portion of the window that extends above the light shelf. The bottom portion of the window contributes daylight only to the narrow zone under the light shelf. The window must face towards the sun for a large part of the time, and outside objects cannot shade it. If the window glazing is tinted or reflective, the daylighting potential is reduced substantially [6].

- The ceiling is another vital part of the system that helps to distribute the sunlight, which is received from light shelves. The ceiling then distributes the light to the occupants. The ceiling plays the same role as the electric lighting equipment. In most cases, the ceiling should be highly reflective to save as much light as possible. The height and orientation of the ceiling and the diffusion characteristics of the ceiling distributes the daylight [16].

A precondition for an effective function of the light shelf system is orientation towards direct sunlight. The windows should face towards the sun for a large portion of the time that the space is occupied. Tinted or reflective glazing may reduce the potential benefit of light shelves, or make them uneconomical. These types of glazing typically block about $70-80 \%$ of incoming sunlight. In some cases, the system may be used with glazing at lower heights where people cannot get close to the glazing [17]. Use of electric light has to be organized and calculated in accordance with the effects and positions of windows which can be improved by light shelves system. The location is apparent for tall windows, where the light shelves can provide deeper penetration than daylighting that is modified by windows shades. [18].

\section{Method Practices and Experimental Test}

\subsection{Site and climate description}

The tested model was located in Ebeltoft, which is a part of Aarhus city. Fig. 4 illuminates the characteristic of this location, oriented towards south; the color of internal space is in general cases (white-gray). Ebeltoft has a humid continental climate with warm summers and no dry sea. The selected site was oriented towards the south at latitude $\mathrm{N} 56^{\circ}, 17^{\prime} .48^{\prime \prime}$ and $\mathrm{E} 10^{\circ}, 41^{\prime} .18^{\prime \prime}$.

The area within $40 \mathrm{~km}$ of this station is covered by oceans and seas (55\%), croplands (37\%), 
grasslands (4\%), and forests (3\%). The cloudiest month of the last 12 months was January, with $94 \%$ of days being more cloudy than clear. Fig. 5 Illustrates the full year of hourly cloud coverage reports in Ebeltoft which is a part of a big city Aarhus.

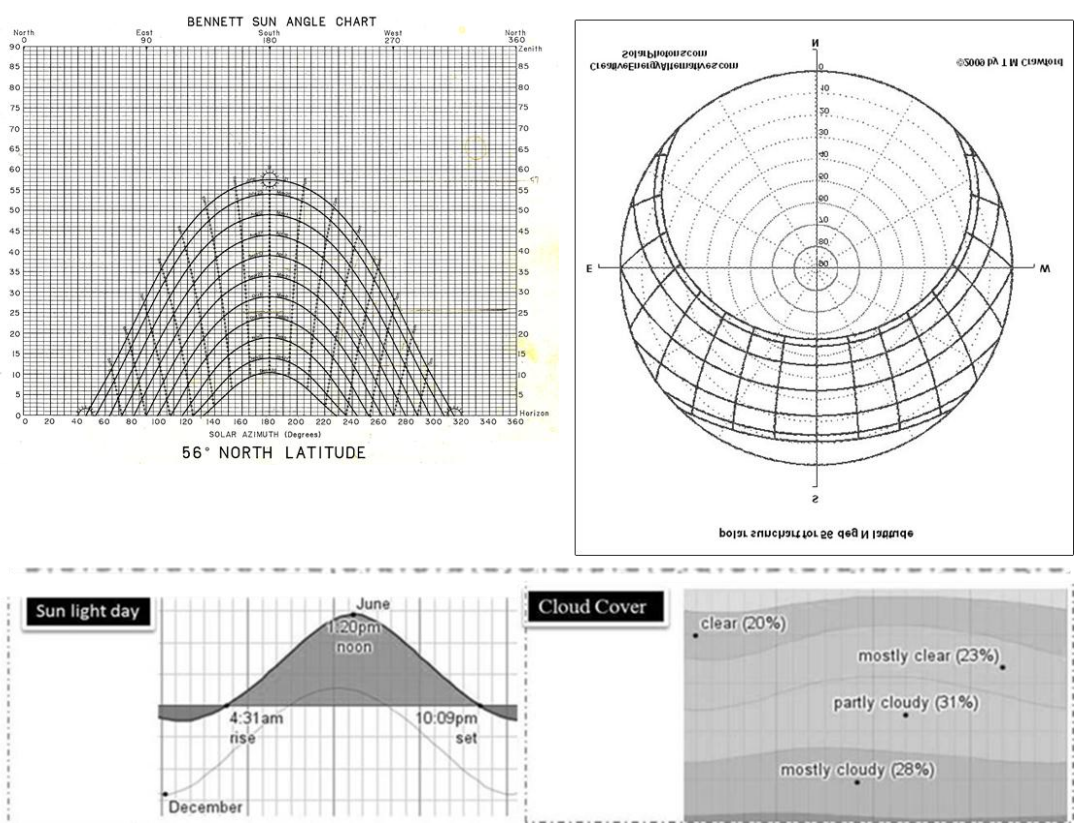

Fig. 4. Bennett sun angle chart for ebeltoft, denmark N 56 [19].

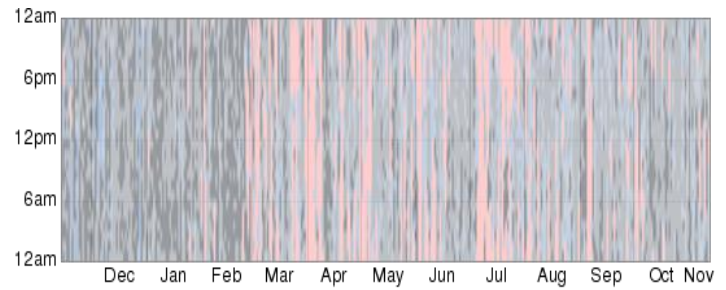

Fig. 5. The full year of hourly cloud coverage reports with the days of the year on the horizontal and the hours of the day on the vertical [20].

The longest period of cloudy weather was from February 3 to February 26, constituting 24 consecutive days that were cloudier than they were clear. Fig. 6 shows Illumination level in testing area from Cl.08 15 on the south face of the house goal.

An analysis related to the window target is illustrated by Fig. 7, where the sun location and sun movement in various seasons of the year is showen.

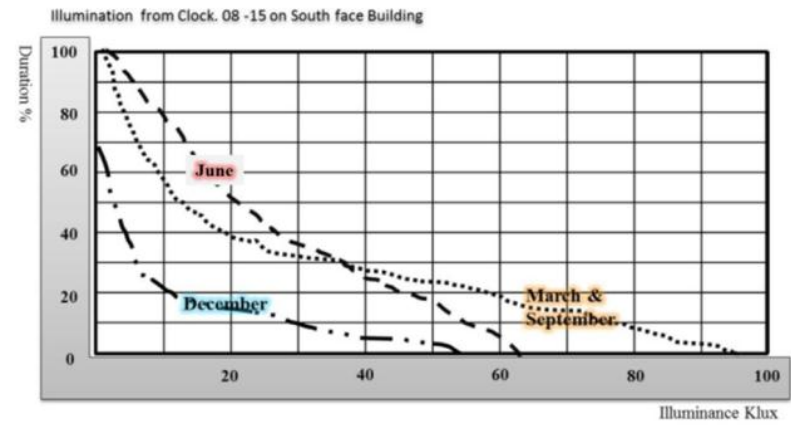

Fig. 6. Illumination level in testing site. 


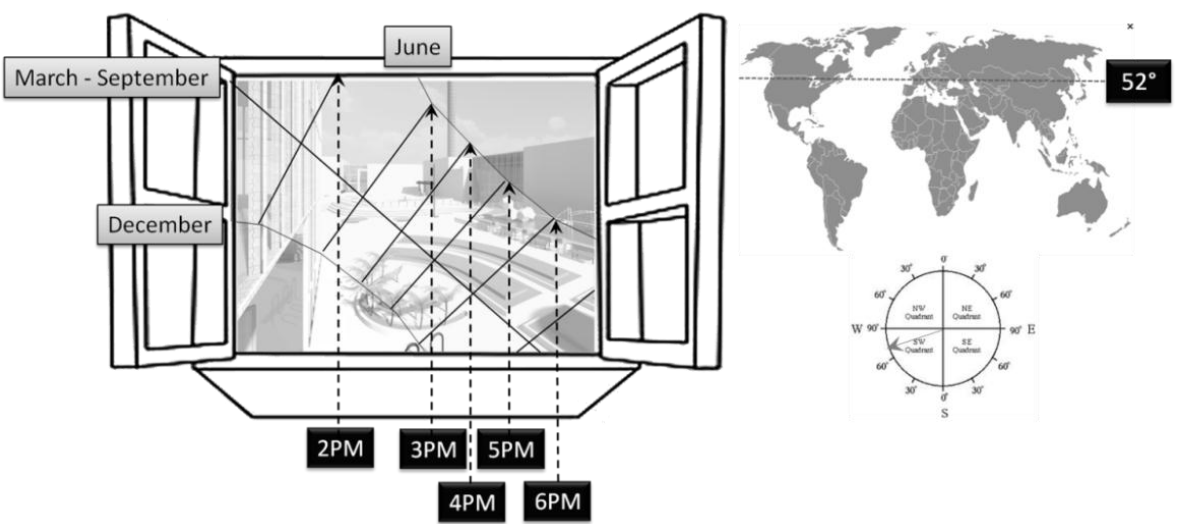

Fig. 7. Solar orbits seen through a testing window facing a south at latitude N56 $17^{\prime} 48^{\prime \prime}$ and E $10^{\circ} 41^{\prime} 18^{\prime \prime}$ hour lines show solar time in Ebeltoft, Denmark.

\subsection{Simulation on tested model}

\section{A. Model in simulated circumstances}

In this model we used simulations to confirm the effect of daylight on inside lighting environments. Precisely we used simulations by radiance. The simulations offered in this test were achieved by means of the original UNIX-based radiance lighting simulation system [21] as well as a Windows version included in the REVIT Desktop program. Radiance is a parameter of programs for the analysis and visualization of lighting in design. It is utilized by architects and engineers to calculate illumination, visual quality and appearance of innovative design spaces, and by researchers to estimate new lighting and daylighting technologies. The main advantage of Radiance over simpler lighting calculation and rendering tools is that there are no limitations on the geometry or materials that may be simulated. Fig. 8 shows the analysis and results made by means of simulation of sun movement in different seasons of the year. Simulation is made by REVIT Desktop program.

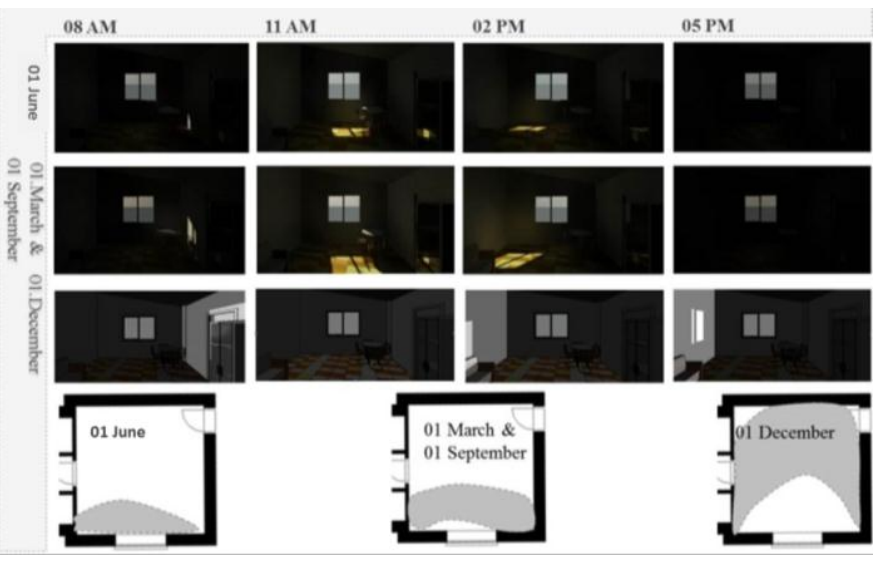

Fig. 8. Simulation sun moving in different season of the year, simulation is making by REVIT Desktop program.

By using the South orientation there were significant areas of luminance in the view towards the window above $2000 \mathrm{~cd} / \mathrm{m}^{2}$ (candela/square meter) from 10:00 - 14:00 hours in the months MarchSeptember. Depending on the transition between the brightest sunlight patches and the surroundings, these luminances could cause glare problems. The most severe problems with high luminance values in the field of view (looking towards the window from the center of the room) occurred during March-April and August-September. In the summer months, May-July, the highest luminances occurred with 3-4 \% of the view above $10000 \mathrm{~cd} / \mathrm{m}^{2}$ [21]. 


\section{B. Experimental Testing model, dimensions and Geometry}

A free horizon (no external obstructions) was assumed, representing habitat space on the site ground. The window has the dimensions $1812 \times 1212 \mathrm{~mm}$ according to Statens Byggeforskningsinstitut SBI (Danish standards). The dimension of the habitat space is $4.6 \mathrm{~m} \times 4.6 \mathrm{~m} \times 2.7 \mathrm{~m}$, (width, depth, height). The relation between window area and habitat space area corresponds to European standards (DS/EN 124641:2011). The inner space was considered unoccupied for this simulation analysis; however different engagements of dividers or furniture can affect straight the output. Fig. 9 shows the geometry and dimensions of the habitat functional space model.

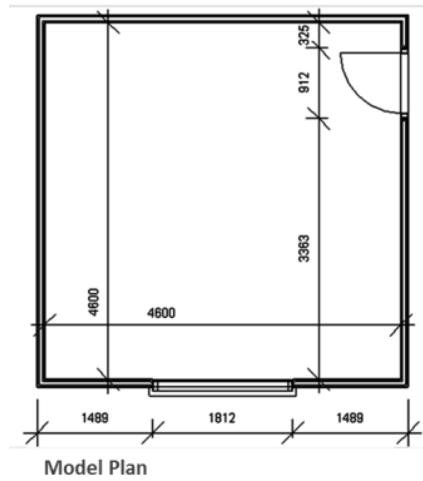

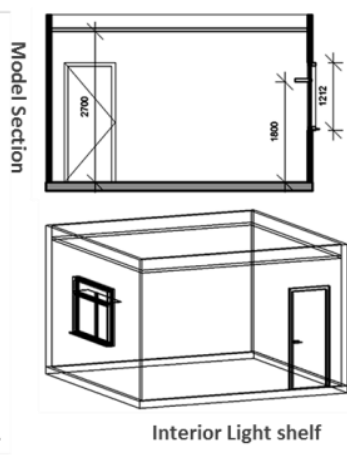

3D model

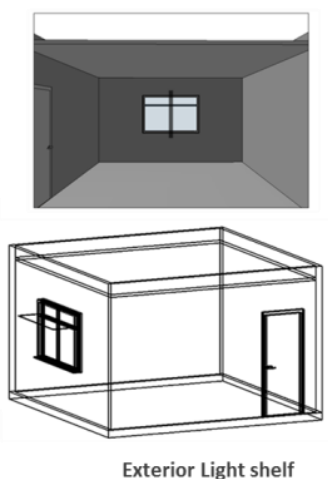

Exterior Light shelf

Fig. 9. Geometry and dimensions of the south-oriented habitat model.

\subsection{Model description}

The two identical experimental models were raised in Ebeltoft, Aarhus, with a scale of 1:1. Each inner space has one window with the dimensions $1812 \mathrm{~mm}$ wide and $1212 \mathrm{~mm}$ high. The window is $0.96 \mathrm{~m}$ from the floor and it is centered with respect to lateral walls. The total area of the window is $1.495 \mathrm{~m}^{2}$, and the area of the habitat space is $21.16 \mathrm{~m}^{2}$. The room models are oriented towards south.

\section{A. Building material description}

The materials, colors and reflectance of the internal walls, floor and ceiling were proposed as follows: Walls are made of Gypsum and ceiling of Suspended tiles and both had white-mat colors, where reflectance materials are 0.81 for walls and 0.81 for ceiling. The floor is made of carpet of grey-matt, in which it had reflectance coefficient of 0.11 .

Choosing gypsum as building material has the following benefits:

- Easy in construction and assembly

- A cheap building material

- Modern and practical

\section{B. Measurement equipment}

Luminous flux (lux) measurements have been made using ShowTech digital lux-meter MK2 with a resolution (0.01 lux). Three measurements have been taken, to calculate the standard deviation, (5 seconds interval). Standard deviation was not higher than $1.5 \%$, in all measurements.

\section{Window description}

The technical description of the window uses in the test is a double-pane assembly with a lowemissivity coating with a U-value of $0.91 \mathrm{~W} / \mathrm{m}^{2} \mathrm{C}$, a light transmittance of $80 \%$ (direct) and $75 \%$ (diffuse), and a reflectance of $14 \%$ (front) and $13 \%$ (back). A model of a portion of a habitat space was determined, with an optimal window size conforming necessity and of natural light quantity and a light shelf model [22]. These high luminance values will certainly cause glare (independent of the background luminance level) and it would be essential, to provide a shading device. Around noon, about $1 \%$ of all values were above 10000 lux in the winter, October-February, for the window. In March and September 
4-5\% of the field of view had luminances above 5000 lux, while in April and August 3-5 \% of the view had luminances above 10000 lux [23].

\section{Light shelves role upon testing model}

The reflective surface in the light shelf system is made of a reflecting zone similar to a mirror. It has the objective to reflect daylight towards the ceiling, to reduce the glare effects of the south part of the building, and to improve lighting levels on the north side. A curved reflective surface area is more efficient, where as a reflective surface that has a matt finish will provide diffuse light with reduced glare, but at the same time the direction cannot be controlled. One rule of thumb for rooms lit from the side is that daylight will at best penetrate into the functional space to about 1.5 the distance from the floor to the upper edge of the ceiling [3]. We used tow types of light shelves in our model: External light shelf and internal light shelf. Variables proposed in this study are the luminance level, dimensional spaces, and the time. Fig. 10 shows the result from the interior space testing model with different positions for the light shelves.
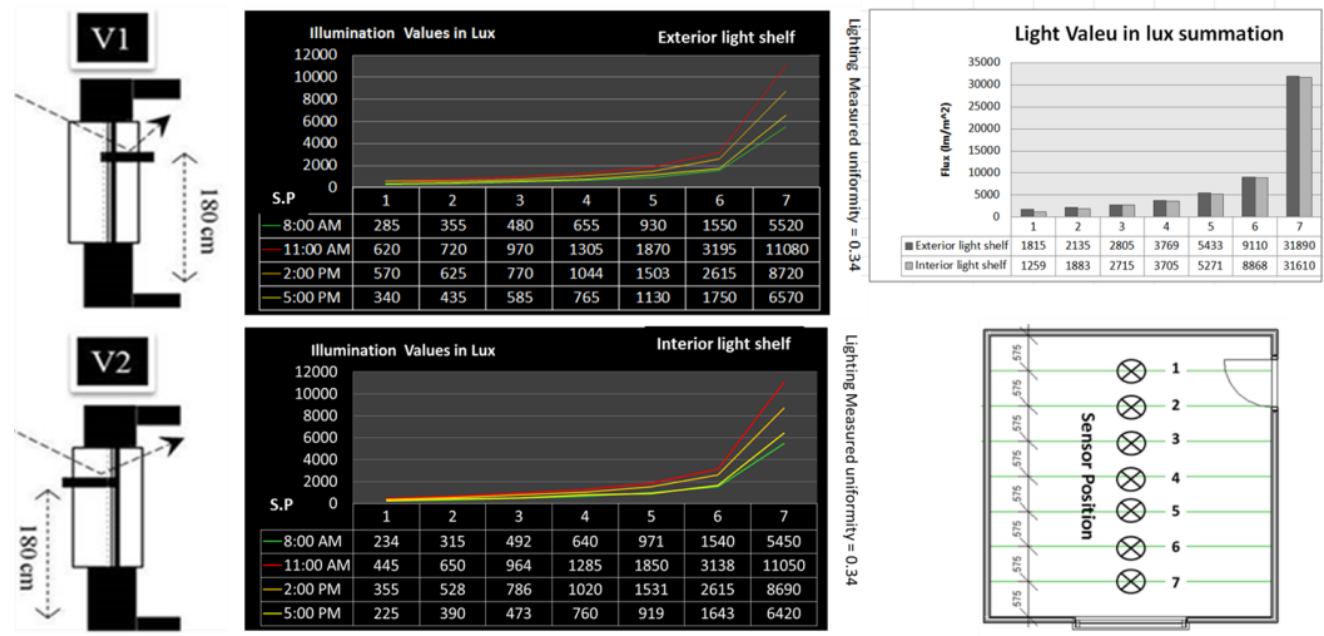

Fig. 10. Lighting measurement in diverse positions of inner space

Practical testing shows that the external light shelf system is more efficient in deeply recessed habitat space compared to internal light shelves but the use of both systems would work best for optimal year round light distribution. An efficient design would need to consider and optimize the best possible arrangement of indoor and outdoor physical devices for best indoor illumination. Under these particular conditions, the external light shelves mounted on a normal window had a higher level of illumination than the internal system because of its position and geometry, with respect to the sun moving trajectory.

\section{Results and Recommendations}

- Light shelves reallocate the sun's direct visible energy deep into a house. They decrease the quantity of radiant energy at the house's edge (which, in turn, decreases the house's cooling load and related energy employment). The incorporation of light shelves to generate high-performance house design needs a holistic approach since, the aesthetics appearance as well as the visual and thermal environments are main design issues. The conception and constructing of light shelves systems needs some corporate sense and careful investigation, where light shelves systems are best functioning with a south-facing glass, light shelves are not optimally operative with east- and west-facing glass. Restricting the size of windows, by the means of blinds or shades, are extra operative means to decrease thermal heat gain and control glare from the low sun angles on these. Light shelves have to be designed to shade the lower parts of the windows and at the same time reflect daylight into the functional internal space. Reflected light is engaged in the direction of the ceiling resulting in a large diffuse light source on the ceiling [24]. 
- Light shelves are not operative utilizing north-facing glass. North-facing skies make available diffuse daylight relatively than direct sunlight for abundant of the year.

- Daylight improvements by using of light shelves do not meaningfully increase the daylight levels in Aarhus city due to an extraordinary ratio of overcast skies in the town. However, the main benefit of the light shelf is to afford shading to the lower part of the windows and consequently decreasing the cooling loads in summer without compromising the benefit of solar gains for the period of winter.

- It has been seen that a small number of the tested cases perform well in terms of daylight but not in terms of energy or vice versa. Thus, a compromise has to be reached, or a definite subject has to be chosen a priority.

- The effect of the light shelf system can harmonize with using the electric lighting in the day time.

- For a competent the working system, all materials have to be checked for quality. It can be achieved by using of innovative profiles and materials to redirect the sun, slab direct sun, and control glare. Glare is not a design issue most of the time; it is critical only when certain viewing condition occurs. In this regard, understanding the conditions that might cause glare is the first step toward finding a design solution to deal with it or to avoid such problems. Additionally the ceiling has to be smooth and lightcolored. Plus light shelves require to be cleaned on a systematic and regular basis. The upper part of the shelf has must be matte white and /or diffusely specular, and not be observable from any point in the habitat space. Tinted glazing use heat absorbing materials dispersed throughout the glass to reduce the amount of solar radiation passing through the glass but at the same time will reduce the amount of visible light passing through the material.

- A curved profile of the reflecting surfaces of the light shelves can create a more effective and correct distribution of light, permitting deeper penetration of glare-free natural daylight.

- It is essential to consider light shelves at the beginning of the design process as they have an effect upon architectural design, but it also has the potential to improve existing building.

- Using of light shelf systems decrease the need for electric light in daytime. An investigation made by D. R. Wulfinghoff 1999 in HVAC about the economical saving potential in light shelf systems shows that the typical energy savings are 30 to 120 watts per meter along the wall. Greater savings are possible with taller windows. External shading is used, and the greatest saving will come from the reduction of cooling load [25].

- For avoiding of thermal bridges in the lighting system, we have to take attention when sun shades are joined to light shelves on the interior. A good design approach includes separation of these two mechanisms by independently attaching them to different framing, and a correct connection throughout the assembly is required to guarantee no thermal breaks occur.

For an effective daylight we recommend tow suggestions

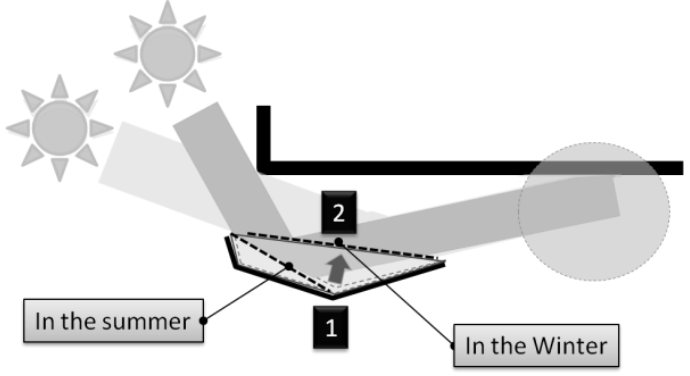

Fig. 11. Flexible innovative of reflective surfaces to coat the main area of inner space.

\section{A. Flexible adaptive reflector}

The light shelf in this system is not difficult to install. Moreover a light shelf system can include two functions, one as a reflection arrangement, which is the main task of the system. And the second is exterior shading device, which is now available from manufacturers as prefabricated components [8]. A flexible reflective surface is a solution for a more sustainable design of the light shelf system. Fig. 11 shows the function of the adaptive light shelf, where the main disadvantage of the light shelve system is:

- Occupancy of a significant portion of windows area 
- Requires periodic cleaning

B. Multi-reflectors solution

One of the most efficient designs of light shelf system consists of a diffusing glass aperture with two reflectors. Diffuses light from the aperture come into edifice within a specified angular range, where angles are set for greatest light distribution and to keep away from glare. The light guiding shade is fitted to deflect direct sun from the window. This solution is suitable for sub tropics, where it directs light effectively into the more recessed functional spaces. The light shelf system can be modified to meet the internal space lighting requirements, which can vary from case to case. The reflecting day light can be accomplished by direct reflection or by diffusion. Fig. 12 shows a solution with a multi-reflectors surfaces model.
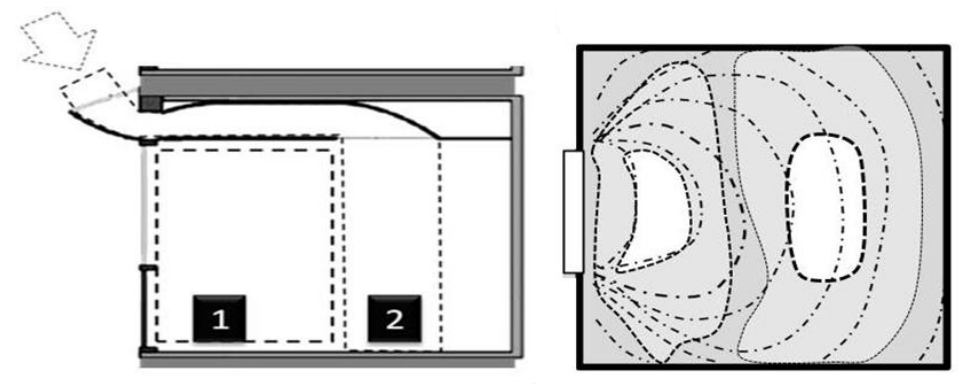

Fig. 12. Light shelves with multi-reflectors.

\section{References}

[1] Gregg D. Ander. AIA, Daylighting Performance and Design. Van Nostrand Reinhold; 1995.

[2] Hopkinson RG. Architectural Physics: Lighting. England: Her Majesty's Stationery Office; 1963.

[3] Corrodi M, Spechtenhauser K. Illuminating, Swiss Federal of Technology Zurich, Birkhauser Verlag AG, Germany; 2008.

[4] Sustainable energy solutions for climate change mitigation [Online]. Available: http://www.sustainability.vic.gov.au/resources/documents/VSII_Sheets_-_light_shelves.pdf

[5] Onai T, Oki M. Daylight factor distribution in interior based upon the mean sky. In: Proc. IBPSA Conference Rio de Janerio, Brazil, 2001.

[6] Almusaed A. Biophilic and Bioclimatic Architecture, Analytical Therapy for the Next Generation of Passive Sustainable Architecture. Under printing. Springer-Verlag London Limited; 2012.

[7] CIBSE Lighting Guide 10: 1999: Daylighting and Window Design, Publisher: CIBSE; 1999.

[8] Nick B, Steemers K. Daylight Design of Buildings. London: James \& James; 2002.

[9] Turner DP, et al. Windows and Environment. Pilkington Brothers Limited; 1971:1.50.

[10] Franco IM. Preliminary comparative study for passive and dynamic shading devices concerning to light and thermal behaviour. In: Proc. 18th International Conference on Passive and Low Energy Architecture 1:305-307, Florianópolis, Hopkinson RG, Collins JB, editors. London: The Ergonomics of Lighting, Macdonald Technical and Scientific, November 7-9, 2001.

[11] Beckett HE, Godfrey JA, Ilium M. Windows Performance, Design and Installation. Crosby Lockwood Staples London; 1974:4.

[12] Baker N, Fanchiotti A, Steemers K. Daylighting in Architecture. James \& James Science Publishers Ltd; 1993:2.7, 2. 8, 2.10.

[13] Scarazzato PS, et al. The dynamic of daylight in tropical humid climates and its influence on indoor environment. In: Proc. of the 7th International Conference on Indoor Air Quality and Climate, Nagoya, Japan, 1996:925-930.

[14] Mardaljevic J. Quantification of parallax errors in sky simulator domes for clear sky conditions. Light Res Technol., 2002; 313-329.

[15] Light shelves for daylighting. [Online]. Available: http://www.faqs.org/patents/app/20100149643

[16] Daylighting in schools. [Online]. Available: http://archrecord.construction.com/resources/conteduc/archives/ 0512lutron-3

[17] Floyd DB, Parker DS. Feld commissioning of a daylight-dimming lighting system. In: Proc. of the 3d European Conference on Energy-Efficient Lighting, Newcastle Upon Tyne, England, 1995:80- 90.

[18] Scarazzato PS, et al. The performance of daylighting systems under partly cloudy skies. In: Proc. of the Performance of Exterior Envelopes of Whole Buildings VII - Integration of Buildings Envelopes, Clearwater Beach, December 2-7, 2001.

[19] Achieving building energy savings with daylighting. [Online]. Available: http://windows.lbl.gov/daylighting/ designguide/ section3.pdf 
[20] Average weather on June 27 for tirstrup near Aarhus, Denmark. [Online]. Available: https://weatherspark.com/averages/28821/6/27/Tirstrup-near-Aarhus-Central-Denmark-Region

[21] Ward LG, Shakespeare R. Rendering with Radiance. The Art and Science of Lighting Visualization. San Francisco (CA): Morgan Kaufmann Publishers; 1998:664.

[22] Love JA. Field performance of daylighting systems with photometric controls. In: Proc. of the $3^{\text {rd }}$ European Conference on Energy-Efficient Lighting, Newcastle Upon Tyne, England, 1995:73-87.

[23] Byggeforskningsinstitut S. Assessment of Daylight Quality in Simple Rooms. Danish Building Research Institute; 2006.

[24] Lam WMC. Sun Lighting as a Form Giver for Architecture. New York: Van Nostrand Reinhold Co.; 1986

[25] Control and use of sunlight. [Online]. Available: http://www.energybooks.com/pdf/10001005.pdf 